\title{
Transcranial Magnetic Stimulation for Drug-Resistant Epilepsies: Rationale and Clinical Experience
}

\author{
Vasilios K. Kimiskidis \\ Department of Neurology III, Aristotle University of Thessaloniki, Thessaloniki, Greece
}

\section{Key Words}

Drug-resistant epilepsies · Epilepsy • Repetitive transcranial magnetic stimulation - Transcranial magnetic stimulation

\begin{abstract}
Transcranial magnetic stimulation (TMS) is a non-invasive brain stimulation technique which, over the last 25 years, has greatly expanded from a simple method for stimulating the motor cortex to an invaluable tool with multiple research, diagnostic and even therapeutic applications. In this review, we discuss the use of repetitive TMS as a means of suppressing cortical hyperexcitability in drug-resistant epilepsies. The theoretical background and the experimental evidence in favor of this novel therapeutic approach are presented, and a number of open-label and controlled studies in patients with various forms of focal epilepsy are reviewed. It is concluded that, although the therapeutic effects of repetitive TMS in epilepsy appear rather limited, further clinical testing of this rapidly evolving technology is warranted.
\end{abstract}

Copyright $\odot 2010$ S. Karger AG, Basel

\section{Introduction}

Transcranial magnetic stimulation (TMS) was developed in 1985 by Anthony Barker at the University of Sheffield [1] and was rapidly endorsed by clinical neurophys- iologists worldwide as a painless and non-invasive means for investigating the excitability of the human brain under physiological and pathological conditions. With regard to epilepsy, the method was primarily used for probing cortical excitability in various epileptic syndromes and for detecting the effects of antiepileptic drugs on excitatory and inhibitory brain mechanisms [2]. TMS has also been used for the preoperative localization of the epileptogenic zone and for mapping functionally important areas of the cortex [3]. Finally, a limited number of recent studies have investigated the therapeutic potential of TMS in treating drug-resistant epilepsies. This latter emerging application will be briefly discussed here.

\section{Theoretical Background and Experimental Studies}

The rationale for using TMS as a therapeutic tool is based on the fact that repetitive TMS (rTMS) can produce effects that outlast the application of a train of stimuli for minutes or hours. It is assumed that these after-effects can be used to modulate neuronal activity in a targeted area of dysfunctional cortex to functional benefit [4]. The exact nature of the TMS-induced effects depends on the frequency, intensity and length of time for which the stimulation is applied. In general, low-frequency rTMS $(\leq 1 \mathrm{~Hz})$ reduces cortical excitability, as evidenced by increased cortical silent period duration [5] and reduced

\section{KARGER}

Fax +41613061234 E-Mail karger@karger.ch www.karger.com

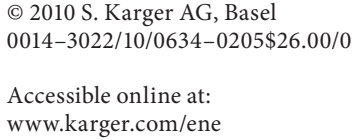


Table 1. Clinical trials and case reports of TMS for drug-resistant epilepsies

\begin{tabular}{|c|c|c|c|c|c|c|}
\hline $\begin{array}{l}\text { Authors } \\
\text { (first author) }\end{array}$ & Subjects & Age & Study design & Epilepsy syndrome & Seizure frequency pre-TMS & AEDs \\
\hline $\begin{array}{l}\text { Cantello } \\
2007[25]\end{array}$ & 43 & $36.9 \pm 13$ & $\begin{array}{l}\text { randomized, double- } \\
\text { blind, sham-controlled }\end{array}$ & $\begin{array}{l}\text { focal }(\mathrm{mTLE}=7, \mathrm{NE}=34) \\
\text { generalized }=2\end{array}$ & $9.1 \pm 2.2 /$ week & $2-4$ \\
\hline $\begin{array}{l}\text { Fregni } \\
2006[23]\end{array}$ & 12 & $21.3 \pm 6.4$ & $\begin{array}{l}\text { randomized, double- } \\
\text { blind, sham-controlled }\end{array}$ & focal (MCD) & $13.6 \pm 10.1 / 28$ days & $1-3$ \\
\hline $\begin{array}{l}\text { Theodore } \\
2002[20]\end{array}$ & 12 & $26-54$ & $\begin{array}{l}\text { randomized, double- } \\
\text { blind, sham-controlled }\end{array}$ & $\begin{array}{l}\text { focal }(m T L E=10,1 T L E=10, \\
\text { ETLE }=4)\end{array}$ & $3.4 \pm 1.2 /$ week & $\geq 2$ \\
\hline $\begin{array}{l}\text { Joo } \\
2007[24]\end{array}$ & 35 & $25(18-46)$ & randomized & $\begin{array}{l}\text { focal }(n=18), \text { multifocal }(n=8) \\
\text { non-localized }(n=9)\end{array}$ & $\begin{array}{l}9.9 \pm 10.1 / \text { week }(\mathrm{NF} \text { group }) \\
7 \pm 9.6 / \text { week }(\mathrm{F} \text { group })\end{array}$ & $\begin{array}{l}3.6 \pm 1.4 \\
(2-7)\end{array}$ \\
\hline $\begin{array}{l}\text { Tergau } \\
2003[21]\end{array}$ & 17 & $29 \pm 10$ & $\begin{array}{l}\text { crossover, placebo- } \\
\text { controlled }\end{array}$ & $\begin{array}{l}\text { mTLE }=2, E T L E=11 \\
\text { multifocal }=2, \text { generalized }=2\end{array}$ & $\begin{array}{l}5.0(1.7-227.5), 0.33 \mathrm{~Hz} \\
6.7(1.2-350), 1 \mathrm{~Hz}\end{array}$ & NR \\
\hline $\begin{array}{l}\text { Daniele } \\
2003[19]\end{array}$ & 4 & $27-33$ & open-label & $\begin{array}{l}\text { focal }(\text { frontal }=2, \text { multifocal }=2 \text {, } \\
\text { due to } C D \text { ) }\end{array}$ & $\begin{array}{l}\text { 19/month (focal), } \\
\text { 36/month (multifocal) }\end{array}$ & $2-3$ \\
\hline $\begin{array}{l}\text { Fregni } \\
2005[18]\end{array}$ & 8 & $14-38$ & open-label & $\begin{array}{l}\mathrm{TLE}=3, \text { multifocal }=4 \\
\mathrm{ETLE}=1, \text { all due to } \mathrm{MCD}\end{array}$ & 4.6/week (3-6.2) & $2-4$ \\
\hline $\begin{array}{l}\text { Kinoshita } \\
2005[17]\end{array}$ & 7 & $16-33$ & open-label & $\begin{array}{l}\text { Focal }(\text { frontal }=5, \text { parietal }=1 \\
\text { hypothalamic hamartoma }=1)\end{array}$ & $16.5 \pm 5.2 /$ week & $2-4$ \\
\hline $\begin{array}{l}\text { Tergau } \\
1999[11]\end{array}$ & 9 & $19-47$ & open-label & $\mathrm{TLE}=2, \mathrm{ETLE}=7$ & $10.3 \pm 6.6 /$ week & various \\
\hline $\begin{array}{l}\text { Brasil-Neto } \\
2004[16]\end{array}$ & 5 & $\begin{array}{l}6,19,30 \\
32,50\end{array}$ & open-label & focal $(\mathrm{TLE}=2, \mathrm{FLE}=3)$ & $1.4 \pm 0.09 /$ day & $1-3$ \\
\hline $\begin{array}{l}\text { Misawa } \\
2005[14]\end{array}$ & 1 & 31 & case report & $\begin{array}{l}\text { epilepsia partialis continua } \\
\text { due to CD }\end{array}$ & EPC & 2 \\
\hline $\begin{array}{l}\text { Rossi } \\
2004[13]\end{array}$ & 1 & 34 & case report & $\begin{array}{l}\text { epilepsia partialis continua } \\
\text { due to CD }\end{array}$ & EPC & 2 \\
\hline $\begin{array}{l}\text { Menkes } \\
2000[12]\end{array}$ & 1 & 38 & case report & ETLE (parietal CD) & 37/month & 3 \\
\hline
\end{tabular}

$\mathrm{CD}=$ Cortical dysplasias; CPS = complex partial seizure; ETLE = extratemporal lobe epilepsy; MCD = malformations of cortical development; $\mathrm{MSO}=$ maximum stimulator output $\mathrm{NE}=$ neocortical epilepsy; $\mathrm{NR}=$ not reported; $\mathrm{TLE}=$ temporal lobe epilepsy $(\mathrm{l}=\mathrm{lateral}$, $\mathrm{m}=\mathrm{mesial}) ; \mathrm{rMT}=\mathrm{resting}$ motor threshold; 0 = circular, 8 = figure-of-eight.

motor-evoked potential amplitudes [6]. In contrast, higher frequencies $(>5 \mathrm{~Hz})$ enhance cortical excitability, particularly if high intensities are used [7]. These effects are reminiscent of long-term depression (LTD) and longterm potentiation, two forms of synaptic plasticity elicited in animal models of cortical circuitry by low- and high-frequency electrical stimulation, respectively. Ac- cordingly, it has been suggested that low-frequency rTMS may exert antiepileptic effects by inducing LTD whereas high-frequency stimulation may act in a proconvulsant manner [2]. While this theoretical framework is appealing, it should be noted that there is in fact very little actual evidence that rTMS induces LTD in the human brain, and other mechanisms including the enhancement of 


\begin{tabular}{|c|c|c|c|c|c|c|c|c|}
\hline \multicolumn{6}{|c|}{ Brain stimulation parameters } & \multicolumn{2}{|l|}{ Outcome } & \multirow[t]{2}{*}{ Adverse effects } \\
\hline $\begin{array}{l}\text { frequen- } \\
\mathrm{cy}, \mathrm{Hz}\end{array}$ & intensity & stimuli & schedule & coil & position & seizures & $\begin{array}{l}\text { epileptiform } \\
\text { discharges }\end{array}$ & \\
\hline 0.3 & $\begin{array}{l}100 \% \operatorname{MT}(\mathrm{n}=34) \\
65 \% \operatorname{MSO}(\mathrm{n}=9)\end{array}$ & $500 /$ train & $\begin{array}{l}2 \text { trains/day } \\
\text { for } 5 \text { days }\end{array}$ & 0 & vertex & no change & decreasing & headache $(\mathrm{n}=7)$ \\
\hline 1 & $70 \% \mathrm{MSO}$ & $1,200 /$ train & $\begin{array}{l}1 \text { train/day } \\
\text { for } 5 \text { days }\end{array}$ & 8 & $\begin{array}{l}\text { epileptogenic focus } \\
(n=9), \text { vertex }(n=3)\end{array}$ & decreasing & decreasing & headache $(\mathrm{n}=3)$ \\
\hline 1 & $120 \% \mathrm{MT}$ & 900/train & $\begin{array}{l}2 \text { trains/day } \\
\text { for } 1 \text { week }\end{array}$ & 8 & epileptogenic area & $\begin{array}{l}\text { trend for } \\
\text { reduction }\end{array}$ & NR & $\begin{array}{l}\text { discomfort }(n=1) \text {, } \\
\text { habitual CPS on two } \\
\text { occasions }(n=1)\end{array}$ \\
\hline 0.5 & $100 \% \mathrm{MT}$ & $\begin{array}{l}3,000 / \text { train } \\
(\mathrm{n}=19) \\
1,500 / \text { train } \\
(\mathrm{n}=16)\end{array}$ & $\begin{array}{l}1 \text { train/day } \\
\text { for } 5 \text { days }\end{array}$ & 0 & $\begin{array}{l}\text { vertex }(n=17) \\
\text { temporal }(n=12)\end{array}$ & $\begin{array}{l}\text { trend for reduc- } \\
\text { tion (correlation } \\
\text { with no. of stimuli) }\end{array}$ & decreasing & headache $(n=3)$ \\
\hline $0.33,1$ & slightly below MT & $1,000 /$ train & $\begin{array}{l}1 \text { train/day } \\
\text { for } 5 \text { days }\end{array}$ & 0 & vertex & $\begin{array}{l}\text { decreasing } \\
\text { (at } 0.33 \mathrm{~Hz} \text { only) }\end{array}$ & NR & none \\
\hline 0.5 & $90 \% \mathrm{MT}$ & $100 /$ train & $\begin{array}{l}\text { biweekly, } \\
4 \text { weeks }\end{array}$ & 8 & $\begin{array}{l}\text { epileptogenic focus } \\
\text { or vertex }\end{array}$ & $\begin{array}{l}\text { decreasing (in } \\
\text { patients with a } \\
\text { single focus) }\end{array}$ & NR & none \\
\hline 0.5 & $65 \% \mathrm{MSO}$ & 600 & $\begin{array}{l}\text { single } \\
\text { session }\end{array}$ & 8 & $\begin{array}{l}\text { epileptogenic focus } \\
\text { or vertex }\end{array}$ & $\begin{array}{l}\text { decreasing } \\
\text { (for } 1 \text { month) }\end{array}$ & $\begin{array}{l}\text { decreasing } \\
\text { (for } \\
1 \text { month) }\end{array}$ & none \\
\hline 0.9 & $90 \%$ rMT & $810 /$ train & $\begin{array}{l}2 \text { trains/day } \\
\text { for } 5 \text { days/week } \\
\text { for } 2 \text { weeks }\end{array}$ & 0 & $\mathrm{FCz}, \mathrm{PCz}$ & decreasing & NR & headache $(n=2)$ \\
\hline 0.33 & $100 \% \mathrm{MT}$ & $1,000 /$ train & $\begin{array}{l}1 \text { train/day } \\
\text { for } 5 \text { days }\end{array}$ & 0 & vertex & decreasing & NR & $\begin{array}{l}\text { partial seizure } \\
\text { after TMS }(n=2)\end{array}$ \\
\hline 0.3 & $95 \% \mathrm{MT}$ & $20 /$ train & $\begin{array}{l}5 \text { trains/day } \\
\text { biweekly for } \\
3 \text { months }\end{array}$ & 0 & vertex & decreasing & NR & NR \\
\hline 0.5 & $90 \%$ rMT & 100 & $\begin{array}{l}\text { single session re- } \\
\text { peated at } 3 \text { months }\end{array}$ & 8 & epileptogenic focus & $\begin{array}{l}\text { decreasing (for } 2 \\
\text { months) }\end{array}$ & NR & none \\
\hline 1 & $90 \%$ rMT & 900 & single session & 8 & epileptogenic focus & decreasing & decreasing & none \\
\hline 0.5 & $95 \%$ rMT & $20 /$ train & $\begin{array}{l}5 \text { trains/day } \\
\text { biweekly for } \\
3 \text { months }\end{array}$ & 0 & epileptogenic focus & decreasing & decreasing & none \\
\hline
\end{tabular}

GABAergic inhibition [8] may be involved in its antiepileptic action.

At an experimental level, low-frequency rTMS $(0.5 \mathrm{~Hz})$ reduced the occurrence of status epilepticus and increased the onset latency of pentylenetetrazole-induced seizures in rats [9]. The duration of the antiepileptic effects is obviously of paramount importance if TMS is to become a clinically meaningful treatment against epilepsy. Ebert and Ziemann [10] reported that a single highfrequency $(20 \mathrm{~Hz})$ rTMS train significantly increased the threshold for induction of epileptic after-discharges in amygdala kindled rats 2 weeks after the stimulating session, indicating that rTMS may confer long-term reduction in seizure susceptibility. 


\section{Clinical Experience and Future Perspectives}

The antiepileptic effects of TMS were initially investigated in a series of open-label studies (table 1). Tergau et al. [21] investigated the effects of low-frequency rTMS in 9 patients with drug refractory partial epilepsies ( 2 temporal, 7 extratemporal) and a mean number of $10.3 \pm 6.6$ partial seizures per week at baseline. Stimulation was performed on 5 consecutive days (two trains of 500 pulses each day at a frequency of $0.33 \mathrm{~Hz}$ ) with a circular coil centered over the vertex. Seizure frequency was reduced by $38.6 \%$ during a 4 -week period after TMS $(\mathrm{p}=0.017)$ but returned to baseline levels after 6-8 weeks. The authors concluded that rTMS may improve pharmaco-resistant epilepsy and ascribed the effects to induction of LTD-like inhibition.

Other single case reports [12-15] and small scale series [16-19] described the effects of TMS on various seizure types (SPS, CPS, sGTCs, myoclonias and absences) due to a wide spectrum of etiologies. Overall, results were encouraging but need to be interpreted cautiously given the uncontrolled design of these studies. Electrographic and clinical improvements were most evident in patients with cortical dysplasia and a single epileptogenic focus. Misawa et al. [14] reported an illustrative case of a 31-year-old patient suffering for 15 years from epilepsia partialis continua (EPC) due to a motor cortical dysplasia. Brain stimulation was performed with a figure-of-eight coil positioned over the left-hand motor area and 100 stimuli were delivered with an intensity of $90 \%$ motor threshold at a frequency of $0.5 \mathrm{~Hz}$. TMS resulted in a dramatic improvement of EPC in the right upper extremity which lasted approximately 2 months. A second trial of rTMS produced similarly good effects.

The enthusiasm created by open-label studies was subsequently tempered by the results of four controlled rTMS studies. Theodore et al. [20] randomized 24 patients with localization-related epilepsy to blinded active or placebo stimulation. Epileptogenic foci were located in the mesial temporal lobe $(\mathrm{n}=10)$, lateral temporal neocortex $(\mathrm{n}=10)$ and extratemporal areas $(n=4)$. Brain stimulation was performed with a figure-of-eight coil positioned over the epileptogenic focus. 900 stimuli were delivered twice daily for a week with an intensity of $120 \%$ motor threshold and a frequency of $1 \mathrm{~Hz}$. The study did not find a statistically significant effect of TMS on partial or secondarily generalized seizures. However, there was a trend towards a short-term decrease in seizure frequency in the active group, detectable during the first 2 weeks post-TMS. There was also a trend for patients with neocortical rath- er than mesial temporal foci to have a greater mean reduction in seizure frequency. The authors provided several explanations for this apparent lack of efficacy including an inadequate sample size, the adoption of a higher stimulation frequency compared to previous 'positive' studies ( 1 vs. $0.33-0.5 \mathrm{~Hz})$ and the inclusion of a significant number of patients with mesial temporal lobe epilepsy. It is clear that patients with deep-seated epileptogenic foci may not be a suitable population for TMS treatment. Currently available TMS techniques enable only superficial stimulation of the brain because the intensity of the induced electric field declines rapidly as a function of the distance between the stimulating coil and the targeted structure. Novel coil designs, such as the H-coil, which achieves effective stimulation of deep brain regions (up to $5 \mathrm{~cm}$ from the scalp) without inducing unbearable fields at the superficial cortex [21], may prove to be more appropriate for stimulating this group of patients.

In 2003, Tergau et al. [21] reported the interim analysis of a crossover, controlled trial involving 17 patients with refractory epilepsy. Two patients suffered from temporal and 11 from extratemporal lobe epilepsies, while 4 patients had multifocal or generalized seizures. Brain stimulation was performed with a circular coil centered over the vertex. 1,000 stimuli daily were delivered for 5 days with an intensity of $100 \%$ resting motor threshold and frequencies of 0.33 or $1 \mathrm{~Hz}$. Interestingly, it was concluded that 0.33 , but not $1 \mathrm{~Hz}$ rTMS, had an antiepileptic effect, whose superiority to placebo almost reached statistical significance $(p=0.062)$. In 2006, Fregni et al. [23] enrolled 21 patients with malformations of cortical development (MCD) and refractory epilepsy in a randomized, double-blind, sham-controlled rTMS trial. Brain stimulation with a figure-of-eight coil was targeted to the area corresponding to the MCD and consisted of 1,200 stimuli daily on 5 consecutive days at a fixed stimulus intensity (70\% maximum stimulator output) with a frequency of $1 \mathrm{~Hz}$. rTMS significantly decreased the number of seizures in the active compared with the sham rTMS group $(p<0.0001)$ and the duration of the effect was at least 2 months. In addition, there was a significant decrease in the number of epileptiform discharges as well as improvement in some aspects of cognitive function in the active rTMS group. The authors ascribed their positive results to various methodological factors including the enrollment of patients with epileptogenic foci in the cortical convexity, precise targeting of the epileptic focus and the use of a fixed, relatively high stimulus intensity. 
In 2007, Joo et al. [24] investigated the effects of rTMS in 35 patients with drug-resistant localization-related epilepsies, divided into a focal $(\mathrm{n}=18)$ and a non-focal group, including 8 subjects with multifocal foci and 9 with nonlocalized epilepsies. Patients were subsequently randomized to receive 3,000 or 1,500 pulses daily, at a frequency of $0.5 \mathrm{~Hz}$ and intensity of $100 \%$ resting motor threshold, for 5 consecutive days. Seizure frequency was not significantly decreased after TMS, although the longer stimulation subgroups tended to have fewer seizures than the shorter ones $(3,000$ pulses $\rightarrow-23 \%, 1,500$ pulses $\rightarrow-3 \%)$. Interictal spikes, however, decreased by $54.9 \%(\mathrm{p}=0.012)$ and totally disappeared in 6 out of 35 subjects.

Finally, in 2007, Cantello et al. [25] conducted a multicenter, randomized, double-blind, sham-controlled, crossover study of rTMS in 43 patients with drug-resistant epilepsy. 19 patients had cryptogenic and 22 symptomatic partial epilepsy, whereas 2 patients suffered from generalized seizures. The majority of them $(n=34)$ suffered from neocortical epilepsy. Brain stimulation was performed with a figure-of-eight coil centered over the vertex. 1,000 stimuli daily were delivered on 5 consecutive days at an intensity of $100 \%$ resting motor threshold and a stimulation frequency of $0.3 \mathrm{~Hz}$. Although no reduction of seizure frequency was observed, active rTMS decreased interictal EEG epileptiform abnormalities significantly in one third of patients. The authors attributed the absence of a clinically detectable effect to various factors such as the inclusion of patients with particularly severe epilepsies receiving heavy polypharmacy (2-4 AEDs) which may have interfered with the molecular and synaptic changes underlying the therapeutic responses to rTMS.
The issue of safety and tolerability of rTMS in patients with epilepsy is obviously of critical importance for any further development of the method as a therapeutic tool. Bae et al. [26] recently summarized the accumulated experience from 26 studies in a total of 280 subjects and concluded that it is generally well tolerated with mild adverse events occurring in $17.1 \%$ of treated subjects, the most common being headache (9.6\%). Seizures occurred in 4 patients ( $1.4 \%$ crude per-subject risk). It is conceivable that in patients with epilepsy, seizures may occur by chance during a TMS session. There is a single case [27] of a seizure with atypical features for that particular patient which appeared to originate from the site of highfrequency $(16 \mathrm{~Hz})$ stimulation and therefore may have been causally related to rTMS. It is concluded that rTMS carries a relatively small risk of inducing seizures in patients with epilepsy, provided the current safety guidelines are strictly followed [28].

TMS has generated hope in the field of epilepsy as a novel neuromodulatory treatment with a number of advantages. It is non-invasive, relatively safe and inexpensive and may potentially induce LTD-like phenomena and reverse the hyperexcitable state of epileptic foci. So far, results have proven to be rather unsatisfactory. However, as Fregni et al. [4] aptly comment, '... noninvasive brain stimulation for epilepsy treatment is still in its infancy'. The clarification of crucial methodological issues (i.e. the best locus for stimulation and the optimal stimulating parameters) in combination with recent technological refinements such as the introduction of the H-coil [22] and the co-registration of EEG with TMS [29] may soon lead to significant advances in the field.

\section{References}

1 Barker A, Freeston I, Jalinous R, Merton P, Morton H: Magnetic stimulation of the human brain. J Physiol 1985;369:3P.

2 Ziemann U: Evaluation of epilepsy and anticonvulsants; in Hallett M, Chokroverty A (eds): Magnetic Stimulation in Clinical Neurophysiology, ed 2. Elsevier ButterworthHeinemann, 2005, pp 253-270.

$\checkmark 3$ Theodore W: Transcranial magnetic stimulation in epilepsy. Epilepsy Curr 2003;3:191197.

4 Fregni F, Pascual-Leone A: Technology insight: noninvasive brain stimulation in neurology - perspectives on the therapeutic potential of rTMS and tDCS. Nat Clin Pract Neurol 2007;3:383-393.

Transcranial Magnetic Stimulation for Drug-Resistant Epilepsies
5 Cincotta M, Borgheresi A, Gambetti C, et al: Subthreshold $0.3-\mathrm{Hz}$ repetitive TMS prolongs the cortical silent period: implications for therapeutic trials in epilepsy. Clin Neurophysiol 2003;114:1827-1833.

6 Muellbacher W, Ziemann U, Boroojerdi B, Hallett M: Effects of low-frequency transcranial magnetic stimulation on motor excitability and basic motor behavior. Clin Neurophysiol 2000;111:1002-1007.

7 Berardelli A, Inghilleri M, Rothwell JC, et al: Facilitation of muscle-evoked responses after repetitive cortical stimulation in man. Exp Brain Res 1998;79-84.

8 Pascual-Leone A, Valls-Sole J, Wassermann EM, Hallett M: Responses to rapid-rate transcranial magnetic stimulation of the human motor cortex. Brain 1994;117:847-858.
19 Akamatsu N, Fueta Y, Endo Y, et al: Decreased susceptibility to pentylenetetrazolinduced seizures after low-frequency transcranial magnetic stimulation in rats. Neurosci Lett 2001;310:153-156.

10 Ebert U, Ziemann U: Altered seizure susceptibility after high-frequency transcranial magnetic stimulation in rats. Neurosci Lett 1999;273:155-158

-11 Tergau F, Naumann U, Paulus W, Steinhoff BJ: Low-frequency repetitive transcranial magnetic stimulation improves intractable epilepsy. Lancet 1999;353:2209.

12 Menkes DL, Gruenthal M: Slow-frequency repetitive transcranial magnetic stimulation in a patient with focal cortical dysplasia. Epilepsia 2000;41:240-242. 
13 Rossi S, Ulivelli M, Bartalini S, et al: Reduction of cortical myoclonus-related epileptic activity following slow-frequency rTMS. Neuroreport 2004;15:293-296.

14 Misawa S, Kuwabara S, Shibuya K, et al: Lowfrequency transcranial magnetic stimulation for epilepsia partialis continua. J Neurol Sci 2005;234:37-39.

15 Conte A, Gilio F, Iacovelli E, et al: Effects of repetitive transcranial magnetic stimulation on spike-and-wave discharges. Neurosci Res 2007;57:140-142.

-16 Brasil-Neto JP, de Araujo DP, Teixeira WA, et al: Experimental therapy of epilepsy by transcranial magnetic stimulation. Arq Neuropsiquiatr 2004;62:21-25.

17 Kinoshita M, Ikeda A, Begum T, et al: Lowfrequency repetitive transcranial magnetic stimulation for seizure suppression in patients with extratemporal lobe epilepsy: a pilot study. Seizure 2005;14:387-392.

18 Fregni F, Thome-Souza S, Bermpohl F, et al: Antiepileptic effects of repetitive transcranial magnetic stimulation in patients with cortical malformations: an EEG and clinical study. Stereotact Funct Neurosurg 2005;83: 57-62.
19 Daniele O, Brighina F, Piazza A, et al: Lowfrequency transcranial magnetic stimulation in patients with cortical dysplasia. A preliminary study. J Neurol 2003:250;761762.

20 Theodore WH, Hunter K, Chen R, et al Transcranial magnetic stimulation for the treatment of seizures: a controlled study. Neurology 2002;59:560-562.

21 Tergau F, Neumann D, Rosenow F, et al: Can epilepsies be improved by repetitive transcranial magnetic stimulation? Interim analysis of a controlled study. Clin Neurophysiol 2003;56(suppl):400-405.

22 Zangen A, Roth Y, Voller B, Hallett M: Transcranial magnetic stimulation of deep brain regions: evidence for efficacy of the $\mathrm{H}$-coil. Clin Neurophysiol 2005;116:775-779.

23 Fregni F, Otachi P, do Valle A, et al: A randomized clinical trial of repetitive transcranial magnetic stimulation in patients with refractory epilepsy. Ann Neurol 2006;60: 447-455.

24 Joo EY, Han SJ, Chung SH, et al: Antiepileptic effects of low-frequency repetitive transcranial magnetic stimulation by different stimulation durations and locations. Clin Neurophysiol 2007;118:702-708.
25 Cantello R, Rossi S, Varrasi C, et al: Slow repetitive TMS for drug-resistant epilepsy: clinical and EEG findings of a placebo-controlled trial. Epilepsia 2007;48:366-374.

-26 Bae EH, Schrader LM, Machii K, et al: Safety and tolerability of repetitive transcranial magnetic stimulation in patients with epilepsy: a review of the literature. Epilepsy Behav 2007; 10:521-528.

$\checkmark 27$ Dhuna A, Gates J, Pascual-Leone A: Transcranial magnetic stimulation in patients with epilepsy. Neurology 1991;41:10671071.

28 Wassermann EM: Risk and safety of repetitive transcranial magnetic stimulation: report and suggested guidelines from the International Workshop on the Safety of Repetitive Transcranial Magnetic Stimulation, June 5-7, 1996. Electroencephalogr Clin Neurophysiol 1998;108:1-16.

29 Komssi S, Kähkönen S: The novelty value of the combined use of electroencephalography and transcranial magnetic stimulation for neuroscience research. Brain Res Rev 2006; 52:183-192. 